\title{
Lifestyle-Related Exposure to Cadmium and Lead Is Associated with Diabetic Kidney Disease
}

\author{
Ilse J. M. Hagedoorn ${ }^{1, *}$, Christina M. Gant ${ }^{2,3, *}$, Sanne v. Huizen ${ }^{1}$, Ronald G. H. J. Maatman ${ }^{4}$, \\ Gerjan Navis $^{3}$, Stephan J. L. Bakker ${ }^{3}$ and Gozewijn D. Laverman ${ }^{1}$ \\ 1 Division of Nephrology, Department of Internal Medicine, Ziekenhuisgroep Twente, 7609 PP Almelo, \\ The Netherlands; s.vanhuizen1@vumc.nl (S.v.H.); g.laverman@zgt.nl (G.D.L.) \\ 2 Department of Internal Medicine, Meander Medisch Centrum, 3813 TZ Amersfoort, The Netherlands \\ 3 Division of Nephrology, Department of Internal Medicine, University of Groningen, \\ University Medical Center Groningen, 9713 GZ Groningen, The Netherlands; g.j.navis@umcg.nl (G.N.); \\ s.j.l.bakker@umcg.nl (S.J.L.B.) \\ 4 Department of Clinical Chemistry, Medlon BV, 7512 KZ Enschede, The Netherlands; r.maatman@zgt.nl \\ * Correspondence: ilse_hagedoorn10@hotmail.com (I.J.M.H.); cm.gant@meandermc.nl (C.M.G.); \\ Tel.: +31-88-7083418 (I.J.M.H.); Fax: +31-88-7087081 (I.J.M.H.)
}

Received: 11 June 2020; Accepted: 28 July 2020; Published: 30 July 2020

\begin{abstract}
Background: Environmental factors contributing to diabetic kidney disease are incompletely understood. We investigated whether blood cadmium and lead concentrations were associated with the prevalence of diabetic kidney disease, and to what extent lifestyle-related exposures (diet and smoking) contribute to blood cadmium and lead concentrations. Material and methods: In a cross-sectional analysis in 231 patients with type 2 diabetes included in the DIAbetes and LifEstyle Cohort Twente (DIALECT-1), blood cadmium and lead concentrations were determined using inductively coupled plasma mass spectrometry. The associations between diet (derived from food frequency questionnaire), smoking and cadmium and lead were determined using multivariate linear regression. The associations between cadmium and lead and diabetic kidney disease (albumin excretion $>30 \mathrm{mg} / 24 \mathrm{~h}$ and/or creatinine clearance $<60 \mathrm{~mL} / \mathrm{min} / 1.73 \mathrm{~m}^{2}$ ) were determined using multivariate logistic regression. Results: Median blood concentrations were $2.94 \mathrm{nmol} / \mathrm{L}$ (interquartile range (IQR): $1.78-4.98 \mathrm{nmol} / \mathrm{L}$ ) for cadmium and $0.07 \mu \mathrm{mol} / \mathrm{L}$ (IQR: $0.04-0.09 \mu \mathrm{mol} / \mathrm{L}$ ) for lead, i.e., below acute toxicity values. Every doubling of lead concentration was associated with a 1.75 (95\% confidence interval (CI): 1.11-2.74) times higher risk for albuminuria. In addition, both cadmium (odds ratio (OR) 1.50 95\% CI: 1.02-2.21) and lead (OR 1.83 95\% CI: 1.07-3.15) were associated with an increased risk for reduced creatinine clearance. Both passive smoking and active smoking were positively associated with cadmium concentration. Alcohol intake was positively associated with lead concentration. No positive associations were found between dietary intake and cadmium or lead. Conclusions: The association between cadmium and lead and the prevalence of diabetic kidney disease suggests cadmium and lead might contribute to the development of diabetic kidney disease. Exposure to cadmium and lead could be a so far underappreciated nephrotoxic mechanism of smoking and alcohol consumption.
\end{abstract}

Keywords: alcohol; cadmium; diabetic kidney disease; diet; lifestyle related exposures; lead; proteinuria; smoking; type 2 diabetes

\section{Introduction}

Diabetic kidney disease (DKD) is one of the most debilitating complications in patients with type 2 diabetes (T2D) [1]. Although effective treatment options are available for reduction of albuminuria, 
blood pressure control and glycemic regulation, progression of DKD into end-stage kidney disease (ESKD) is still common, underlining the necessity to identify additional mechanisms to target for renoprotection [2-4]. Exposure to the heavy metals cadmium $(\mathrm{Cd})$ and lead $(\mathrm{Pb})$ could be interesting in this respect. $\mathrm{Cd}$ and $\mathrm{Pb}$ bind to low-molecular-weight proteins, which are freely filtered through the glomerulus and then reabsorbed by the proximal tubules, causing primary tubular toxicity [5]. This may lead to albuminuria and progressive kidney disease towards ESKD [6].

High-grade exposure to $\mathrm{Cd}$ and/or $\mathrm{Pb}$ is undoubtedly nephrotoxic [5-7]. Moreover, evidence suggests that low blood levels of $\mathrm{Cd}$ and/or $\mathrm{Pb}$ already have unwarranted effects, as associations have been found between limited $\mathrm{Cd}$ and/or Pb blood concentrations and renal tubular defect markers, reduced eGFR and/or albuminuria [8-13]. These associations appear to be dose-dependent [8-12].

Despite a general reduction of industrial exposure to $\mathrm{Cd}$ and $\mathrm{Pb}$ over the past decades, exposure to these metals is still present in the population at a lower grade, in particular, through smoking and ingestion of food (from contaminated soil and water) [7,14].

Patients with T2D are at risk of developing DKD and may be more vulnerable to the nephrotoxic effects of low-grade $\mathrm{Cd}$ and $\mathrm{Pb}$ exposure [8,15-19]. However, epidemiological studies on the nephrotoxic effects of low-level $\mathrm{Cd}$ and $\mathrm{Pb}$ exposure in patients with T2D are scarce. Therefore, in this study in patients with T2D, we examine (1) the association between several lifestyle-related exposures, such as smoking and dietary intake, and the $\mathrm{Cd}$ and $\mathrm{Pb}$ blood concentrations and (2) the association between low-level $\mathrm{Cd}$ and $\mathrm{Pb}$ exposure and the prevalence of $\mathrm{DKD}$.

\section{Materials and Methods}

\subsection{Patient Inclusion}

This study was performed in the DIAbetes and LifEstyle Cohort Twente-1 (DIALECT-1), which was previously described in detail [20]. All adult patients with T2D treated in the outpatient clinic internal medicine/nephrology in the Ziekenhuisgroep Twente Hospital, Almelo and Hengelo, the Netherlands, were eligible for participation. Exclusion criteria were ESKD and inability to understand the informed consent procedure. Patients were included between 2009 and 2016. The study was performed in accordance with the Helsinki agreement and the guidelines of good clinical practice. Prior to participation, all patients signed an informed consent form. DIALECT was approved by the local institutional review boards (METC-registration numbers NL57219.044.16 and 1009.68020) and was registered in the Netherlands Trial Register (NTR trial code 5855).

\subsection{Data Collection}

Information on medical conditions and medication use was obtained from electronic patient files and verified with the patient during the baseline visit. Information on smoking habits was collected through questionnaires. Diet and alcohol consumption were assessed with a Food-Frequency Questionnaire, which was previously validated [21]. Anthropometric measurements and presence of diabetic polyneuropathy were obtained from physical examination. The body surface area (BSA) was calculated using the universally adopted formula of DuBois [22]. Blood pressure was measured in supine position with an automated device (Dinamap ${ }^{\circledR}$; GE Medical systems, Milwaukee, WI, USA) for $15 \mathrm{~min}$ with one-minute intervals. The mean systolic and diastolic pressure of the last three measurements was used to estimate the mean arterial pressure (MAP), which was used for further analysis. The MAP was calculated by the following formula: $(2 \times$ diastolic blood pressure + systolic blood pressure)/3. Microvascular complications were defined as the presence of polyneuropathy, diabetic kidney disease and/or retinopathy. Macrovascular complications were defined as the presence of peripheral arterial disease, coronary artery disease and/or cerebrovascular disease. Venous blood and $24 \mathrm{~h}$ urine samples were stored at $-80^{\circ} \mathrm{C}$ for later analysis. 


\subsection{Measures of Diabetic Kidney Disease}

In our cohort study, we aimed for extensive and deep phenotyping. Therefore we included collection of $24 \mathrm{~h}$ urine, to provide objective data on nutritional intake, including sodium intake. Furthermore, determination of $24 \mathrm{~h}$ urinary creatinine excretion allows for calculation of the glomerular filtration rate with serum creatinine while correcting for muscle mass of the individual, in contrast to the estimated glomerular filtration rate (eGFR) formulas, which correct serum creatinine for average muscle mass on a population scale. This allows not only for estimation of individual renal function with higher precision, but also for analyses with creatinine clearance as a continuous variable, because it is well-known that imprecision of eGFR as an estimate of renal function at higher estimated GFR levels is even greater than it is in the lower range [23]. So, we used creatinine clearance calculated from $24 \mathrm{~h}$ urinary creatinine excretion and corrected for BSA as primary endpoint [24]. DKD was defined as creatinine clearance $<60 \mathrm{~mL} / \mathrm{min} / 1.73 \mathrm{~m}^{2}$ and/or the presence of albuminuria ( $24 \mathrm{~h}$ urinary albumin excretion $>30 \mathrm{mg} /$ day). Secondary analyses were performed with albuminuria based on albumin/creatinine ratio in $24 \mathrm{~h}$-urine or morning void $(>2.5 \mathrm{mg} / \mathrm{mmol}$ for men and $>3.5 \mathrm{mg} / \mathrm{mmol}$ for women).

\section{4. $\mathrm{Cd}$ and $\mathrm{Pb}$ Measurements}

Blood $\mathrm{Cd}$ and $\mathrm{Pb}$ concentrations were determined from EDTA whole blood. Samples were diluted $30 \times$ using $0.2 \% \mathrm{v} / \mathrm{v} \mathrm{HNO}_{3} 0.05 \% \mathrm{v} / \mathrm{v}$ Triton $1 \% \mathrm{v} / \mathrm{v}$ Methanol and analysed by inductively coupled plasma mass spectrometry (ICP-MS) using a kinetic energy discrimination procedure on the Perkin Elmer Nexion300× ICP-MS. Instrumentation settings are depicted in Supplementary Table S1. Levels below the limit of detection were entered just below the limit value. For $\mathrm{Cd}, 4$ of the 240 patients had values below the limit of detection (LOQ $1 \mathrm{nmol} / \mathrm{L}$ ). For $\mathrm{Pb}$, no patients had values below the limit of detection (LOQ $21 \mathrm{nmol} / \mathrm{L}$ ). Reference values were used as described, $\mathrm{Cd}<5.0 \mu \mathrm{g} / \mathrm{L}[25]$ and $\mathrm{Pb}<50.0 \mu \mathrm{g} / \mathrm{L}[26]$.

\subsection{Statistical Analyses}

All statistical analyses were performed using SPSS statistics (IBM SPSS Statistics for Windows, Version 23.0, Armonk, New York, NY, USA). Normality of data was determined by visual inspection of histograms. Data were presented as mean \pm standard deviation (normal distribution), as median and interquartile range (IQR 25th-75th percentile, skewed data), or in number and percentage (categorical data). Patients with missing data on $\mathrm{Cd}$ and/or $\mathrm{Pb}$ were excluded from the study. Cases with otherwise missing data were excluded from the respective analyses. We performed transformation of the concentrations of $\mathrm{Cd}$ and $\mathrm{Pb}$ according to logarithm with base 2, which allows for interpretation of ORs per doubling of concentrations of $\mathrm{Cd}$ and $\mathrm{Pb}$. Univariate linear regression analyses were performed to identify potential confounders in associations of $\mathrm{Cd}$ and $\mathrm{Pb}$ concentrations with variables of interest.

We used multivariate linear regression analyses to evaluate the determinants of blood concentration of $\mathrm{Cd}$ and $\mathrm{Pb}$. A $p$-value $<0.05$ was considered statistically significant. To evaluate the association between dietary intake and $\mathrm{Cd}$ and $\mathrm{Pb}$ concentration, the average total caloric intake and $\mathrm{g} / \mathrm{day}$ of different food groups were ranked in tertiles. The two highest tertiles of several food products were compared with the lowest tertile in multivariate linear regression analyses. Supplementary Table S2 shows the components of the different food groups, i.e., vegetables, potatoes, liver and kidney, rice, bread, fish, fruit and cacao. To determine the association between $\mathrm{Cd}, \mathrm{Pb}$ and $\mathrm{DKD}$, a multivariate logistic regression analyses was performed using albuminuria $(24 \mathrm{~h}$ urinary albumin excretion $>30 \mathrm{mg} / 24 \mathrm{~h}$ ) and creatinine clearance $<60 \mathrm{~mL} / \mathrm{min} / 1.73 \mathrm{~m}^{2}$ as primary outcome variables. Potential confounders were based on previous literature and univariate correlations. Potential interaction of associations of $\mathrm{Cd}$ and $\mathrm{Pb}$ with albuminuria and creatinine clearance $<60 \mathrm{~mL} / \mathrm{min} / 1.73 \mathrm{~m}^{2}$ by age, sex, smoking and alcohol intake was evaluated by inclusion of product-terms for these respective variables with $\mathrm{Cd}$ and $\mathrm{Pb}$ in the logistic regression analyses. In secondary analyses, logistic regression analyses was performed by employing the albumin/creatinine ratio as the outcome variable. 


\section{Results}

\subsection{Patient Characteristics, $\mathrm{Cd}$ and $\mathrm{Pb}$ Concentrations}

$\mathrm{Cd}$ and $\mathrm{Pb}$ were determined in the first 240 patients included in DIALECT-1. In total, 231 patients were included in the analysis, and patients were excluded from the study if $24 \mathrm{~h}$-urine was not available $(n=1)$ or if they were determined to be type 1 diabetics $(n=8)$. The characteristics of the study population $(n=231)$ are shown in Table 1 . Mean age was $64 \pm 9$ years and the majority were men $(60 \%)$. The median duration of diabetes was 12 (6-20) years. In total, 105 patients (46\%) had DKD, of which 47 patients (20\%) had a creatinine clearance $<60 \mathrm{~mL} / \mathrm{min} / 1.73 \mathrm{~m}^{2}$ and 86 patients (37\%) had albuminuria (>30 mg/24 h). Mean HbA1c was $7.2 \pm 3.1 \%$ (55 $\pm 10 \mathrm{mmol} / \mathrm{mol})$ and 140 patients $(61 \%)$ were on insulin therapy. The number of micro- $(67 \%)$ and macrovascular complications $(43 \%)$ was high. Median blood concentrations were $2.94 \mathrm{nmol} / \mathrm{L}(1.78-4.98 \mathrm{nmol} / \mathrm{L})$ for Cd and $0.07 \mu \mathrm{mol} / \mathrm{L}$ (0.04-0.09 $\mu \mathrm{mol} / \mathrm{L})$ for $\mathrm{Pb}$. All values were considered as otherwise 'normal' levels for $\mathrm{Cd}$ and $\mathrm{Pb}$.

Table 1. Baseline characteristics and univariate associations with $\mathrm{Cd}$ and $\mathrm{Pb}$.

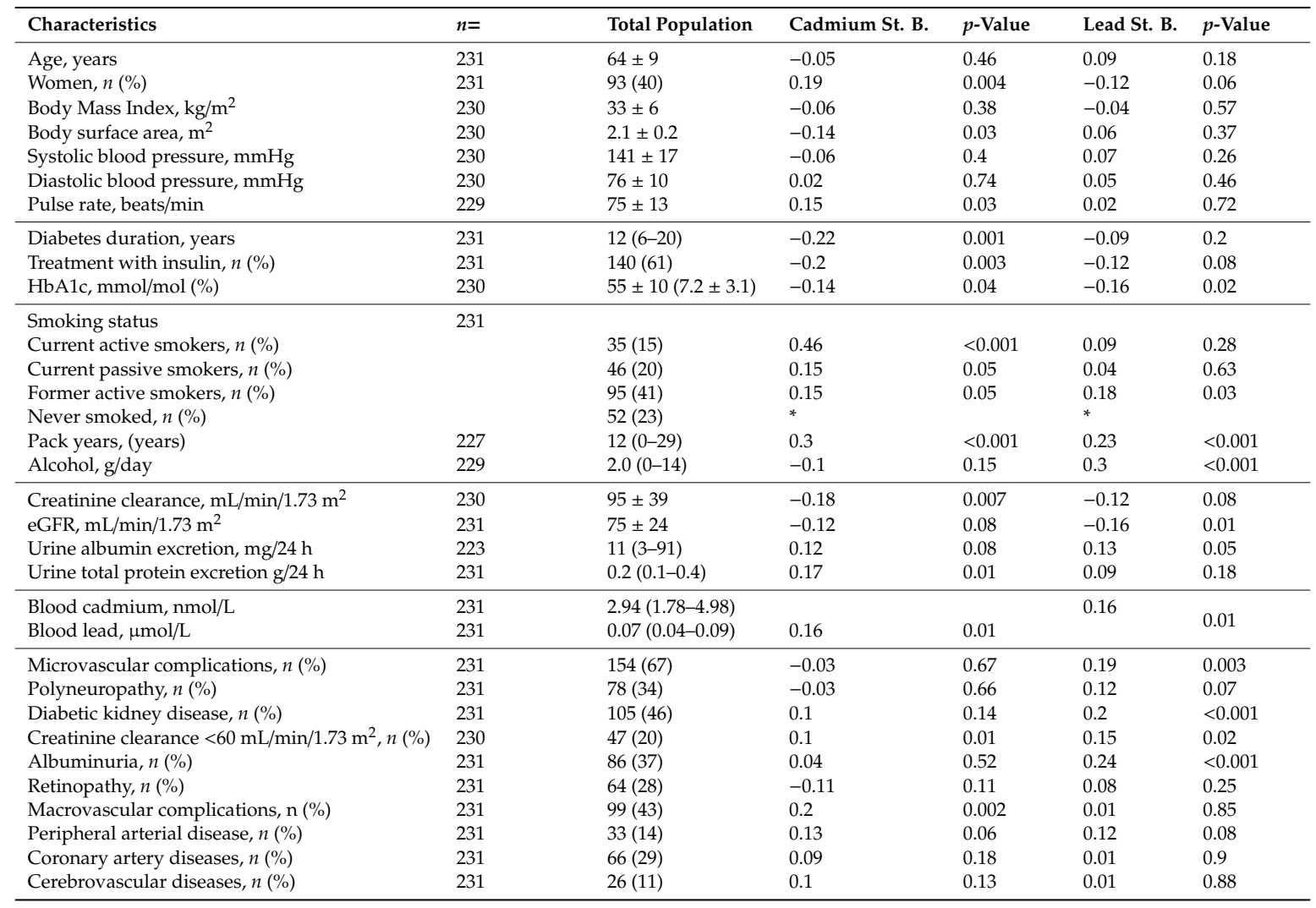

Standardized beta (St. B.) is shown. ${ }^{*}$ never smoked is used as the reference value for smoking status. eGFR: estimated glomerular filtration rate.

\subsection{Determinants of $\mathrm{Cd}$ and $\mathrm{Pb}$ Concentrations}

Univariate associations between study parameters and $\mathrm{Cd}$ and $\mathrm{Pb}$ are shown in Table 1 . Blood $\mathrm{Cd}$ concentration was higher in women $(\beta=0.19, p=0.004)$ and in patients with exposure to smoking (pack years $\beta=0.30, p<0.001$; active smoking $\beta=0.46, p<0.001$ ). In addition, $\mathrm{Cd}$ was inversely associated with years of diabetes, insulin use and serum $\mathrm{HbA} 1 \mathrm{c}$. In multivariate analyses, the $\mathrm{Cd}$ concentration was significantly higher in active, passive and former smokers, compared to never smokers (Table 2). The association between alcohol and $\mathrm{Cd}$ remain statistically nonsignificant. 
Table 2. Multivariate linear regression analyses on smoking status and alcohol intake and Cd and $\mathrm{Pb}$ concentrations.

\begin{tabular}{|c|c|c|c|c|}
\hline \multirow{2}{*}{ Lifestyle-Related Exposures } & \multicolumn{2}{|c|}{ Cadmium nmol/L } & \multicolumn{2}{|c|}{ Lead umol/L } \\
\hline & St. B. & $p$-Value & St. B. & $p$-Value \\
\hline \multicolumn{5}{|l|}{ Active smoker } \\
\hline Model 1 (crude) & 0.46 & $<0.001$ & 0.08 & 0.27 \\
\hline Model 2 (adjusted) & 0.50 & $<0.001$ & 0.11 & 0.16 \\
\hline Model 3 (adjusted) & 0.48 & $<0.001$ & 0.02 & 0.86 \\
\hline \multicolumn{5}{|l|}{ Passive smoker } \\
\hline Model 1 (crude) & 0.16 & 0.04 & -0.003 & 0.97 \\
\hline Model 2 (adjusted) & 0.17 & 0.03 & -0.001 & 0.99 \\
\hline Model 3 (adjusted) & 0.17 & 0.03 & -0.03 & 0.69 \\
\hline \multicolumn{5}{|l|}{ Former smoker } \\
\hline Model 1 (crude) & 0.17 & 0.03 & 0.14 & 0.08 \\
\hline Model 2 (adjusted) & 0.25 & 0.002 & 0.17 & 0.05 \\
\hline Model 3 (adjusted) & 0.22 & 0.005 & 0.12 & 0.16 \\
\hline \multicolumn{5}{|l|}{ Alcohol intake } \\
\hline Model 1 (crude) & -0.09 & 0.17 & 0.29 & $<0.001$ \\
\hline Model 2 (adjusted) & 0.003 & 0.96 & 0.30 & $<0.001$ \\
\hline Model 3 (adjusted) & -0.05 & 0.49 & 0.30 & $<0.001$ \\
\hline
\end{tabular}

Standardized beta (St. B.) is shown. Alcohol intake in g/day. Never-smoked is used as the reference value for smoking status. Model 1 is unadjusted (crude), while Model 2 is adjusted for age, sex, creatinine clearance and Model 3 is adjusted for Model 2 and lead (for cadmium) and cadmium (for lead).

With respect to blood $\mathrm{Pb}$ concentration, both smoking (pack years $\beta=0.23, p<0.001$, former smoking $\beta=0.18 p=0.03)$ and alcohol intake $(\beta=0.30, p<0.001)$ were univariately associated with $\mathrm{Pb}$ concentrations. Alcohol intake remained significantly associated with $\mathrm{Pb}$ concentration in the fully adjusted model ( $\beta=0.30, p<0.001$ ), while the association between smoking and $\mathrm{Pb}$ was not observed in the fully adjusted model (Table 2). $\mathrm{Cd}$ and $\mathrm{Pb}$ concentrations were associated with one another $(\beta=0.16, p=0.01)$.

\subsection{Dietary Intake and Blood $\mathrm{Cd}$ and $\mathrm{Pb}$ Concentrations}

The average daily intake of different food products is shown in Supplementary Table S3. The mean caloric intake was $1850 \pm 619 \mathrm{kcal} /$ day. No positive associations were found between the two highest tertiles of different food products and the $\mathrm{Cd}$ and $\mathrm{Pb}$ concentrations, neither after adjustment for possible confounders and the total caloric intake (Table 3). Interestingly, a significant inverse association was observed between the highest tertiles of vegetables and fruits and the $\mathrm{Cd}$ concentration compared with the lowest tertiles ( $\beta=-0.16, p=0.03$ and $\beta=-0.14, p=0.05$, respectively).

\subsection{Multivariate Analysis between $\mathrm{Cd}$ and $\mathrm{Pb}$ and Diabetic Kidney Disease}

Subsequently, we investigated the associations between $\mathrm{Cd}$ and $\mathrm{Pb}$, and $24 \mathrm{~h}$ urinary albumin excretion $\left(>30 \mathrm{mg} / 24 \mathrm{~h}\right.$ ) and creatinine clearance $<60 \mathrm{~mL} / \mathrm{min} / 1.73 \mathrm{~m}^{2}$ (Table 4). Doubling of the $\mathrm{Pb}$ concentration was strongly associated with albuminuria (OR 1.75, 95\% CI: 1.11-2.74), which remained unchanged in the fully adjusted model. There was no significant association between $\mathrm{Cd}$ and albuminuria. Secondary analysis with albumin/creatinine ratio as the outcome variable instead of $24 \mathrm{~h}$ albuminuria yielded similar results (Supplementary Table S4). There was a significant association between $\mathrm{Cd}$ and albumin/creatinine ratio, however this association may be accounted for mostly by smoking and $\mathrm{Pb}$ as this association became statistically nonsignificant when adjusting for these confounders. Doubling of the $\mathrm{Cd}$ and $\mathrm{Pb}$ concentrations was significantly associated with creatinine clearance $<60 \mathrm{~mL} / \mathrm{min} / 1.73 \mathrm{~m}^{2}$ (respectively, OR 1.50 95\% CI: $1.02-2.21$ and 1.83 95\% CI: 1.07-3.15), even when adjusting for the other metal (Table 4). We found no indication for effect-modification of associations of $\mathrm{Cd}$ and $\mathrm{Pb}$ with albuminuria and reduced creatinine clearance (all $p$-values for interaction terms $>0.10$ ). 
Table 3. Multivariate linear regression between different food products as independent variables and the $\mathrm{Cd}$ and $\mathrm{Pb}$ concentrations as dependent variables.

\begin{tabular}{|c|c|c|c|c|c|c|c|c|}
\hline \multirow{3}{*}{ Food Products } & \multicolumn{4}{|c|}{ Cadmium (nmol/L) } & \multicolumn{4}{|c|}{ Lead $(\mu \mathrm{mol} / \mathrm{L})$} \\
\hline & \multicolumn{2}{|c|}{ Crude } & \multicolumn{2}{|c|}{ Adjusted * } & \multicolumn{2}{|c|}{ Crude } & \multicolumn{2}{|c|}{ Adjusted * } \\
\hline & St. B. & $p$ Value & St. B. & $p$ Value & St. B. & $p$ Value & St. B. & $p$ Value \\
\hline \multicolumn{9}{|l|}{ Vegetable } \\
\hline Tertile 2 & -0.15 & 0.06 & -0.13 & 0.06 & 0.06 & 0.47 & 0.09 & 0.21 \\
\hline Tertile 3 & -0.16 & 0.03 & -0.16 & 0.03 & -0.02 & 0.81 & 0.01 & 0.93 \\
\hline \multicolumn{9}{|l|}{ Rice } \\
\hline Tertile 2 & -0.01 & 0.95 & -0.02 & 0.81 & -0.08 & 0.32 & -0.06 & 0.42 \\
\hline Tertile 3 & -0.06 & 0.42 & -0.02 & 0.81 & -0.16 & 0.14 & -0.1 & 0.2 \\
\hline \multicolumn{9}{|l|}{ Potatoes } \\
\hline Tertile 2 & -0.12 & 0.13 & -0.12 & 0.11 & 0.14 & 0.08 & 0.11 & 0.14 \\
\hline Tertile 3 & -0.13 & 0.1 & -0.13 & 0.1 & 0.02 & 0.83 & 0.02 & 0.86 \\
\hline \multicolumn{9}{|l|}{ Bread } \\
\hline Tertile 2 & -0.07 & 0.34 & -0.05 & 0.48 & 0.07 & 0.36 & 0.1 & 0.18 \\
\hline Tertile 3 & -0.15 & 0.06 & -0.06 & 0.46 & 0.02 & 0.83 & 0.08 & 0.31 \\
\hline \multicolumn{9}{|l|}{ Fish } \\
\hline Tertile 2 & 0.01 & 0.9 & -0.01 & 0.9 & 0.05 & 0.53 & 0.07 & 0.32 \\
\hline Tertile 3 & -0.02 & 0.77 & 0.2 & 0.78 & 0.05 & 0.56 & 0.02 & 0.84 \\
\hline \multicolumn{9}{|l|}{ Fruit } \\
\hline Tertile 2 & -0.18 & 0.02 & -0.08 & 0.24 & -0.03 & 0.66 & -0.02 & 0.8 \\
\hline Tertile 3 & -0.15 & 0.05 & -0.14 & 0.05 & 0.03 & 0.69 & 0 & 0.99 \\
\hline \multicolumn{9}{|l|}{ Liver and kidney } \\
\hline Tertile 2 & -0.12 & 0.09 & -0.8 & 0.25 & -0.15 & 0.03 & -0.11 & 0.1 \\
\hline Tertile 3 & -0.16 & 0.02 & -0.12 & 0.07 & -0.01 & 0.88 & 0.02 & 0.8 \\
\hline \multicolumn{9}{|l|}{ Cacao } \\
\hline Tertile 2 & -0.11 & 0.18 & -0.07 & 0.32 & -0.05 & 0.53 & -0.01 & 0.1 \\
\hline Tertile 3 & -0.08 & 0.3 & -0.03 & 0.66 & -0.1 & 0.22 & -0.02 & 0.76 \\
\hline
\end{tabular}

* Adjusted for: age, sex, total caloric intake, creatinine clearance $\left(\mathrm{mL} / \mathrm{min} / 1.73 \mathrm{~m}^{2}\right)$, pack years, alcohol intake (g/day), $\mathrm{Pb}$ (for $\mathrm{Cd}$ ) and $\mathrm{Cd}$ (for $\mathrm{Pb}$ ). $\mathrm{Cd}$ and $\mathrm{Pb}$ as dependent continuous variables.

Table 4. Multivariate logistic regression on the association between $\mathrm{Cd}$ and $\mathrm{Pb}$ and albuminuria and reduced creatinine clearance.

\begin{tabular}{|c|c|c|c|c|}
\hline \multirow{2}{*}{ Independent Variables } & \multicolumn{2}{|c|}{ Creatinine Clearance $<60 \mathrm{~mL} / \mathrm{min} / 1.73 \mathrm{~m}^{2}$} & \multicolumn{2}{|c|}{ Albuminuria $>30 \mathrm{mg} / 24 \mathrm{~h}$} \\
\hline & OR & $95 \% \mathrm{CI}$ & OR & $95 \% \mathrm{CI}$ \\
\hline \multicolumn{5}{|c|}{ Cadmium nmol/L } \\
\hline Model 1 (crude) & 1.57 & $1.14-2.16$ & 1.08 & $0.85-1.37$ \\
\hline Model 2 & 1.65 & $1.18-2.31$ & 1.22 & $0.95-1.58$ \\
\hline Model 3 & 1.53 & $1.08-2.17$ & 1.24 & $0.95-1.62$ \\
\hline Model 4 & 1.52 & $1.07-2.16$ & 1.24 & $0.95-1.63$ \\
\hline Model 5 & 1.57 & $1.07-2.30$ & 1.06 & $0.80-1.41$ \\
\hline Model 6* & 1.50 & $1.02-2.21$ & 1.01 & $0.75-1.36$ \\
\hline \multicolumn{5}{|c|}{ Lead $\mu \mathrm{mol} / \mathrm{L}$} \\
\hline Model 1 (crude) & 1.65 & $1.07-2.55$ & 2.15 & $1.44-3.19$ \\
\hline Model 2 & 1.68 & $1.06-2.66$ & 1.98 & $1.31-2.98$ \\
\hline Model 3 & 1.63 & $1.01-2.66$ & 1.97 & $1.29-3.01$ \\
\hline Model 4 & 1.94 & $1.16-3.24$ & 1.93 & $1.25-3.00$ \\
\hline Model 5 & 1.94 & $1.15-3.27$ & 1.75 & $1.12-2.74$ \\
\hline Model $6^{* *}$ & 1.83 & $1.07-3.15$ & 1.75 & $1.11-2.74$ \\
\hline
\end{tabular}

Odds ratio (OR) and 95\% confidence interval (CI) are shown. Model 1 is unadjusted (crude), Model 2 is adjusted for age, sex, Model 3 is adjusted for Model 2 and HbA1c, insulin use, years diabetes, mean arterial pressure, Model 4 is adjusted for Model 3 and alcohol intake (g/day), Model 5 is adjusted for Model 4 and pack years and Model 6 is adjusted for Model 5 and * lead (for cadmium) and ** cadmium (for lead). The ORs for the additional independent variables of Model 6 are listing in Supplementary Table S5. 


\section{Discussion}

Cadmium $(\mathrm{Cd})$ and Lead $(\mathrm{Pb})$ are two of the most prevalent and nephrotoxic heavy metals [27]. Evidence suggests that patients with T2D are more susceptible to renal toxic effects of Cd and $\mathrm{Pb}[8,15-19,28]$. In our study, with concentrations of $\mathrm{Cd}$ and $\mathrm{Pb}$ considerably below the values for acute toxicity, we found clear associations between these elements and albuminuria and reduced creatinine clearance, respectively, in patients with T2D. Doubling of the $\mathrm{Pb}$ concentration was associated with a 1.75 times higher risk of albuminuria. Additionally, both higher $\mathrm{Cd}$ and $\mathrm{Pb}$ revealed an increased risk of creatinine clearance $<60 \mathrm{~mL} / \mathrm{min} / 1.73 \mathrm{~m}^{2}$. Furthermore, smoking and alcohol intake appear to be associated with the $\mathrm{Cd}$ and $\mathrm{Pb}$ concentrations, respectively.

Although no lower limit of blood $\mathrm{Pb}$ and $\mathrm{Cd}$ for (nephro)toxicity had been established previously $[18,27]$, the $\mathrm{Cd}$ and $\mathrm{Pb}$ concentrations found in this study were all in the supposedly normal range, as found in Europe and the United States $[8,9,11]$. In the general population, previous studies have described the associations between $\mathrm{Cd}$ and $\mathrm{Pb}$ exposure and reduced eGFR or creatinine clearance, but with higher blood levels, i.e., $\mathrm{Cd} \geq 0.60 \mu \mathrm{g} / \mathrm{L}(5.34 \mathrm{nmol} / \mathrm{L})$ and $\mathrm{Pb}>1.82 \mu \mathrm{g} / \mathrm{dL}$ $(0.09 \mu \mathrm{mol} / \mathrm{L})[8-11]$. The current study is the first to investigate these associations in a population of both men and women with complicated T2D [28]. We used two different, creatinine-based measures to assess renal function, i.e., eGFR and creatinine clearance. While the association with creatinine clearance was significant for $\mathrm{Cd}$, and the associations with eGFR for $\mathrm{Pb}$, with borderline associations between creatinine clearance and $\mathrm{Pb}$, and between eGFR and $\mathrm{Cd}$, respectively, the consistency of the direction of the associations supports the robustness of our findings.

With respect to albuminuria, we found no positive association between $\mathrm{Cd}$ and albuminuria, which is in line with previous studies in the general population [11,29]. In secondary analyses, the association between $\mathrm{Cd}$ and albumin/creatinine ratio may be attributed mostly to smoking (pack years) and Pb concentrations. However, we did find higher concentrations of $\mathrm{Cd}$ in women, and it has been shown previously that women with T2D have a higher risk for albuminuria from cadmium exposure compared to women without T2D [28]. Moreover, Madrigal and colleagues found that the association between Cd and eGFR was more pronounced among females in the general population [12]. When the interaction term between $\mathrm{Cd}$ and sex was added to the adjusted models for creatinine clearance $<60 \mathrm{~mL} / \mathrm{min} / 1.73 \mathrm{~m}^{2}$ and albuminuria, we found no significant interactions ( $p=0.54, p=0.89$, respectively).

For $\mathrm{Pb}$, several prospective studies in patients with and without T2D have found that environmental $\mathrm{Pb}$ accelerates progressive kidney disease (based on the creatinine clearance) $[17,19,30,31]$, overruling negative findings in cross-sectional studies $[9,11]$. Two studies in patients with T2D have shown that $\mathrm{Pb}$ concentrations of 4-6 times higher than our population, were associated with an increased long-term risk for progressive kidney disease [17,19]. Moreover, the glomerular filtration rate improved in these patients after lead-chelation therapy [17]. Whether these Pb concentrations are 'low-level' is debatable, and due to sociodemographic differences, these results cannot be extended to our study population. We found a strong association between $\mathrm{Pb}$ and albuminuria and reduced creatinine clearance in a much lower concentration than previously described. Although causality cannot be proven, this suggests that $\mathrm{Pb}$ exposure may enhance DKD in a much lower concentration than previously thought. Possibly, patients with T2D are more susceptible to renal damage due to $\mathrm{Pb}$ exposure than the general population, or the mechanism of nephrotoxicity of $\mathrm{Pb}$ in $\mathrm{T} 2 \mathrm{D}$ differs from the mechanism in the nondiabetic population.

Our study was not designed to investigate the mechanisms of renal damage by $\mathrm{Cd}$ and $\mathrm{Pb}$, but in the literature several mechanisms have been implicated [5-7,15,19,27,32]. Even though both metals bind to low-molecular-weight proteins and primarily affect the proximal tubules, renal outcomes tend to diverge-while Cd-induced renal impairment is characterized in the early stages by the presence of increased excretion of LMWH proteins ( $\beta 2$-microglobuline, retinol binding protein and a1-microglobulin), in $\mathrm{Pb}$ nephropathy, the proteinuria (including albuminuria) is absent or minimal in the early stages of renal diseases [27]. 
However, both metals seem to interfere with diabetes metabolism in a way that might interact with the process of DKD. For Cd, the background of hyperglycaemia appears to provide an environment which promotes $\mathrm{Cd}$-induced renal impairment in diabetes [15]. In diabetic obese mice, a Cd-induced proteinuria increase was achieved with a 4-fold lower $\mathrm{Cd}$ than those in nondiabetic control mice [33]. Moreover, Cd exposure causes abnormal adipocyte differentiation, expansion and function, which might lead to development of insulin resistance, hypertension and cardiovascular diseases [34]. We found that longer duration of diabetes and higher $\mathrm{HbA} 1 \mathrm{c}$ were associated with lower cadmium levels, which is somewhat counterintuitive, but in line with findings of a previous study in patients with established T2D [35]. A possible explanation is that this is the consequence of healthy survivor bias. For $\mathrm{Pb}$, one hypothesis is that low-level environmental $\mathrm{Pb}$ exposure can lead to oxidative stress reactions causing functional nitric oxide deficiency and activation of the renin-angiotensin-aldosterone system in patients with diabetes [19]. Lead chelation therapy can improve renal function through potential interference with this mechanism by reducing the reactive oxygen species $[17,19]$.

The nephrotoxic effects of low-level $\mathrm{Cd}$ exposure in the general population are still under debate $[11,29,36,37]$. Several studies have described a pattern of increased blood Cd, and decreased urine $\mathrm{Cd}$ concentrations combined with a decreased eGFR, which might suggest reverse causality (increased blood $\mathrm{Cd}$ concentrations due to reduced renal clearance) $[11,29]$. Therefore, prospective studies on the association between Cd and eGFR trajectory are warranted.

In our study, current smokers have a 2.5 times higher $C d$ concentration compared with nonsmokers. Additionally, even former- and passive smoking were positively associated with the Cd concentration, which is in line with previous findings [38]. Noting the association between $\mathrm{Cd}$ and reduced creatinine clearance, kidneys should be added to the long list of organs negatively affected by smoking. Although dietary intake of cereals, vegetables or shellfish is reported to be the most important source of cadmium in the nonsmoking population, we found no positive association between diet and $\mathrm{Cd}$ concentration $[7,18]$. This could be due to the fact that patients in this study have a relatively low intake of food categories which contain high amounts of $\mathrm{Cd}$, for example only 12 patients reach the recommended average daily intake of $250 \mathrm{~g}$ vegetables per day. Interestingly, we found a negative association between the two highest tertiles of vegetables and fruit intake and Cd concentrations. This may be accounted for by residual confounding whereby more vegetable and fruit intake may reflect a healthier lifestyle, or maybe vegetables and fruit stimulate the clearance of cadmium in the body. For blood $\mathrm{Pb}$ concentration, alcohol intake was the most important contributing parameter. This might be explained by intake of Pb-contaminated alcoholic liquors [39]. According to a study into $\mathrm{Pb}$ in alcohol beverages, draught beers sampled contained greater than $10 \mu \mathrm{g} / \mathrm{L} \mathrm{of} \mathrm{Pb}$ and $4 \%$ contained greater than $100 \mu \mathrm{g} / \mathrm{L}$ of $\mathrm{Pb}$ [39]. Consumption of beer containing $50 \mu \mathrm{g} / \mathrm{L}$ of lead could make a substantial contribution to blood $\mathrm{Pb}$ concentrations in man. Consumption of $11 /$ day of wine containing $150 \mu \mathrm{g} / \mathrm{L}$ of lead could also make a major contribution to blood lead concentrations [39].

One strength of our study is the fact that a population of patients with T2D in only one geographic area was studied, and therefore environmental differences were minimized. Furthermore, albuminuria and renal function were based on the $24 \mathrm{~h}$ urine collection, instead of a single portion of urine as in most earlier studies. We found a lower creatinine clearance to be significantly associated with higher cadmium and lower eGFR to be significant associated with higher lead, while creatinine clearance was not significantly associated with lead level and eGFR was not significantly associated with cadmium level. It should be noted that although the latter associations were not significant, this was due to the fact that the magnitude of the associations was slightly smaller than that of the significant associations rather than that they were absent or inverse. With a larger sample size, these associations would likely also have been significant and congruent with the significant associations of lower creatinine clearance with higher cadmium and lower eGFR with higher lead. A limitation of our study is the cross-sectional design, allowing only research of associations rather than causality. However, even when the associations we found were based on reverse causality, this might be of great importance because it may implicate toxic accumulation of $\mathrm{Cd}$ and $\mathrm{Pb}$. In patients with $\mathrm{T} 2 \mathrm{D}$ maintenance haemodialysis, 
higher $\mathrm{Cd}$ levels were associated with increased hazard ratio for all-cause mortality (hazard ratio $(\mathrm{HR})=2.34(1.10-4.96))[40]$.

Although the overall $\mathrm{Pb}$ exposure levels have diminished in recent decades due to elimination of $\mathrm{Pb}$ from gasoline, there is still an under-recognized but persistent occurrence of $\mathrm{Cd}$ and $\mathrm{Pb}$ exposure in urban populations [32]. Due to industrial emissions and household waste from batteries, cosmetics, and painting, the soil becomes polluted and $\mathrm{Cd}$ and $\mathrm{Pb}$ end up in water and food products. Possibly, due to urbanisation, exposure to $\mathrm{Cd}$ from food products will increase in the coming years [7]. Considering that even low doses of $\mathrm{Cd}$ and $\mathrm{Pb}$ are likely to have harmful effects, the lifestyle-related exposures to $\mathrm{Cd}$ and $\mathrm{Pb}$ remain an important research topic which has several policy implications for public health.

In conclusion, our study revealed that in patients with T2D lifestyle-related $\mathrm{Pb}$ exposure is associated with the prevalence DKD in much lower concentrations than previously described. Although prospective studies are required to confirm a causal relationship, patients with T2D may be at increased risk for the toxic effects of low-level $\mathrm{Cd}$ and $\mathrm{Pb}$ exposure. Our study provides additional affirmation that avoiding possible exposure to $\mathrm{Cd}$ and $\mathrm{Pb}$ through smoking and alcohol intake is important in T2D.

Supplementary Materials: The following are available online at http://www.mdpi.com/2077-0383/9/8/2432/s1, Table S1: Perkin Elmer Nexion300× ICP-MS instrumentation, Table S2: Overview of food items included in each food category, Table S3: Daily amounts of dietary intake, Table S4: Multivariate logistic regression between Cd and $\mathrm{Pb}$ and albumin/creatinine ratio. Table S5: Multivariate logistic regression on the association between $\mathrm{Cd}$ and $\mathrm{Pb}$ and albuminuria and reduced creatinine clearance.

Author Contributions: I.J.M.H. researched data and wrote the manuscript, C.M.G., S.J.L.B. and G.D.L. researched data and reviewed/edited the manuscript. G.N. and S.v.H. reviewed/edited the manuscript. R.G.H.J.M. determined the $\mathrm{Cd}$ and $\mathrm{Pb}$ concentrations and contributed to the research design and methods. G.D.L. is the principal investigator of DIALECT and guarantor. All authors have read and agreed to the published version of the manuscript.

Funding: This study was financially supported by an unrestricted grant from AstraZeneca.

Acknowledgments: The authors would like to thank all students who have participated in DIALECT-1, Ziekenhuisgroep Twente, for their contribution to patient inclusion. The authors would like to thank Milou Oosterwijk for her assistance with the analyses with the food frequency questionnaire and MEDLON B.V. and staff members of the laboratory for the cooperation and their contribution to the determinations.

Conflicts of Interest: The authors declare no conflict of interest.

$\begin{array}{ll}\text { Abbreviations } & \\ \text { BSA } & \text { Body surface area } \\ \text { T2D } & \text { Type 2 diabetes } \\ \mathrm{Cd} & \text { Cadmium } \\ \mathrm{DIALECT} & \text { DIAbetes and LifEstyle Cohort Twente } \\ \mathrm{DKD} & \text { Diabetic kidney disease } \\ \mathrm{ESKD} & \text { End stage kidney disease } \\ \mathrm{ICP}-\mathrm{MS} & \text { Inductively coupled plasma mass spectrometry } \\ \mathrm{MAP} & \text { Mean arterial pressure } \\ \mathrm{Pb} & \text { Lead }\end{array}$

\section{References}

1. Atkins, R.C.; Zimmet, P. Diabetic kidney disease: Act now or pay later. J. Bras. Nefrol. 2010, 23, 7-10.

2. Ruggenenti, P.; Fassi, A.; Llieva, A.P.; Bruno, S.; Iliev, I.P.; Brusegan, V.; Rubis, N.; Gherardi, G.; Arnoldi, F.; Ganeva, M.; et al. Preventing microalbuminuria in type 2 diabetes. N. Engl. J. Med. 2004, 351, 1941-1951. [CrossRef] [PubMed]

3. Remuzzi, G.; Macia, M.; Ruggenenti, P. Prevention and Treatment of Diabetic Renal Disease in Type 2 Diabetes: The BENEDICT Study. J. Am. Soc. Nephrol. 2006, 17, S90-S97. [CrossRef] [PubMed] 
4. Zoungas, S.; De Galan, B.E.; Ninomiya, T.; Grobbee, D.; Hamet, P.; Heller, S.R.; MacMahon, S.; Marre, M.; Neal, B.; Patel, A.; et al. Combined Effects of Routine Blood Pressure Lowering and Intensive Glucose Control on Macrovascular and Microvascular Outcomes in Patients With Type 2 Diabetes. Diabetes Care 2009, 32, 2068-2074. [CrossRef]

5. Madden, E.F.; Fowler, B.A. Mechanisms of nephrotoxicity from metal combinations: A review. Drug Chem. Toxicol. 2000, 23, 1-12. [CrossRef]

6. Johri, N.; Jacquillet, G.; Unwin, R. Heavy metal poisoning: The effects of cadmium on the kidney. Biometals 2010, 23, 783-792. [CrossRef]

7. Jarup, L.; Bergulund, M. Health effects of cadmium exposure-A review of the literature and risk estimate. Scand. J. Work Environ. Health 1998, 24, 1-52.

8. Åkesson, A.; Lundh, T.; Vahter, M.; Bjellerup, P.; Lidfeldt, J.; Nerbrand, C.; Samsioe, G.; Strömberg, U.; Skerfving, S. Tubular and Glomerular Kidney Effects in Swedish Women with Low Environmental Cadmium Exposure. Environ. Health Perspect. 2005, 113, 1627-1631. [CrossRef]

9. Navas-Acien, A.; Tellez-Plaza, M.; Guallar, E.; Muntner, P.; Silbergeld, E.; Jaar, B.; Weaver, V.M. Blood Cadmium and Lead and Chronic Kidney Disease in US Adults: A Joint Analysis. Am. J. Epidemiol. 2009, 170, 1156-1164. [CrossRef]

10. Ferraro, P.M.; Costanzi, S.; Naticchia, A.; Sturniolo, A.; Gambaro, G. Low level exposure to cadmium increases the risk of chronic kidney disease: Analysis of the NHANES 1999-2006. BMC Public Health 2010, 10, 1-8. [CrossRef]

11. Buser, M.C.; Ingber, S.Z.; Raines, N.; Fowler, D.A.; Scinicariello, F. Urinary and blood cadmium and lead and kidney function: NHANES 2007-2012. Int. J. Hyg. Environ. Health 2016, 219, 261-267. [CrossRef]

12. Madrigal, J.M.; Ricardo, A.C.; Persky, V.; Turyk, M. Associations between blood cadmium concentration and kidney function in the U.S. population: Impact of sex, diabetes and hypertension. Environ. Res. 2019, 169, 180-188. [CrossRef]

13. Buchet, J. Renal effects of cadmium body burden of the general population. Lancet 1990, 336, 699-702. [CrossRef]

14. Satarug, S. Dietary Cadmium Intake and Its Effects on Kidneys. Toxics 2018, 6, 15. [CrossRef]

15. Edwards, J.R.; Prozialeck, W.C. Cadmium, diabetes and chronic kidney disease. Toxicol. Appl. Pharmacol. 2009, 238, 289-293. [CrossRef]

16. Kim, N.H.; Hyun, Y.Y.; Lee, K.-B.; Chang, Y.; Rhu, S.; Oh, K.-H.; Ahn, C. Environmental Heavy Metal Exposure and Chronic Kidney Disease in the General Population. J. Korean Med. Sci. 2015, 30, $272-277$. [CrossRef]

17. Lin, J.-L.; Lin-Tan, D.-T.; Yu, C.-C.; Li, Y.; Huang, Y.-Y.; Li, K.-L. Environmental exposure to lead and progressive diabetic nephropathy in patients with type II diabetes. Kidney Int. 2006, 69, 2049-2056. [CrossRef]

18. Satarug, S.; Haswell-Elkins, M.R.; Moore, M.R. Safe levels of cadmium intake to prevent renal toxicity in human subjects. Br. J. Nutr. 2000, 84, 791-802. [CrossRef]

19. Huang, W.-H.; Lin, J.-L.; Lin-Tan, D.-T.; Hsu, C.-W.; Chen, K.-H.; Yen, T.-H. Environmental Lead Exposure Accelerates Progressive Diabetic Nephropathy in Type II Diabetic Patients. BioMed Res. Int. 2013, 2013, 742545. [CrossRef]

20. Gant, C.M.; Binnenmars, S.H.; Berg, E.V.D.; Bakker, S.J.; Navis, G.J.; Laverman, G.D. Integrated Assessment of Pharmacological and Nutritional Cardiovascular Risk Management: Blood Pressure Control in the DIAbetes and LifEstyle Cohort Twente (DIALECT). Nutrients 2017, 9, 709. [CrossRef]

21. Feunekes, G.I.; Van Staveren, W.A.; De Vries, J.H.; Burema, J.; Hautvast, J.G. Relative and biomarker-based validity of a food-frequency questionnaire estimating intake of fats and cholesterol. Am. J. Clin. Nutr. 1993, 58, 489-496. [CrossRef]

22. Du Bois, D.; Du Bois, E.F. A formula to estimate the approximate surface area if height and weight be known. 1916. Nutrients 1989, 5, 303-311.

23. Coresh, J.; Astor, B.C.; McQuillan, G.; Kusek, J.; Greene, T.; Van Lente, F.; Levey, A.S. Calibration and random variation of the serum creatinine assay as critical elements of using equations to estimate glomerular filtration rate. Am. J. Kidney Dis. 2002, 39, 920-929. [CrossRef] 
24. Inker, L.A.; Perrone, R.D. Calculation of the Creatinine Clearance. 2017. Available online: https://www-uptodate-com.proxy-ub.rug.nl/contents/calculation-of-the-creatinineclearance?search= Calculation $\% 20$ of $\% 20$ the $\% 20$ creatinine $\% 20$ clearance\&source=search_result\&selectedTitle $=4 \sim\{\} 150 \&$ usage_type $=$ default\&display_rank $=4$ (accessed on 4 October 2019).

25. Moreau, T.; Lellouch, J.; Juguet, B.; Festy, B.; Orssaud, G.; Claude, J.R. Blood Cadmium Levels in a General Male Population with Special Reference to Smoking. Arch. Environ. Health Int. J. 1983, 38, 163-167. [CrossRef]

26. Nader, R.; Horwath, A.R.; Wittwer, C.T. Chapter 42: Toxic Elements. In Tietz Textbook of Clinical Chemistry and Molecular Diagnostics, 6th ed.; Elsevier: St. Louis, MO, USA, 2017; pp. 907-910.

27. Gonick, H.C. Nephrotoxicity of cadmium \& lead. Indian J. Med. Res. 2008, 128, 335-352.

28. Barregard, L.; Bergström, G.; Fagerberg, B. Cadmium, type 2 diabetes, and kidney damage in a cohort of middle-aged women. Environ. Res. 2014, 135, 311-316. [CrossRef]

29. Chaumont, A.; Nickmilder, M.; Dumont, X.; Lundh, T.; Skerfving, S.; Bernard, A. Associations between proteins and heavy metals in urine at low environmental exposures: Evidence of reverse causality. Toxicol. Lett. 2012, 210, 345-352. [CrossRef]

30. Lin, J.-L.; Lin-Tan, D.-T.; Li, Y.-J.; Chen, K.-H.; Huang, Y.-L. Low-level Environmental Exposure to Lead and Progressive Chronic Kidney Diseases. Am. J. Med. 2006, 119, 707.e1-707.e9. [CrossRef]

31. Lin, J.-L.; Lin-Tan, D.-T.; Hsu, K.-H.; Yu, C.-C. Environmental Lead Exposure and Progression of Chronic Renal Diseases in Patients without Diabetes. N. Engl. J. Med. 2003, 348, 277-286. [CrossRef]

32. Leff, T.; Stemmer, P.; Tyrrell, J.; Jog, R. Diabetes and Exposure to Environmental Lead (Pb). Toxics 2018, 6, 54. [CrossRef]

33. Jin, T.; Nordberg, G.F.; Sehlin, J.; Leffler, P. The susceptibility of spontaneously diabetic mice cadmium-metallothionein nephrotoxicity. Toxicology 1994, 89, 81-90. [CrossRef]

34. Kawakami, T.; Sugimoto, H.; Furuichi, R.; Kadota, Y. Cadmium reduces adipocyte size and expression levels of adiponectin and Peg1/Mest in adipose tissue. Toxicology 2010, 267, 20-62. [CrossRef]

35. Anetor, J.I.; Uche, C.Z.; Ayita, E.B.; Adedapo, S.K.; Adeleye, J.O.; Anetor, G.O.; Akinlade, S.K. Cadmium Level, Glycemic Control, and Indices of Renal Function in Treated Type II Diabetics: Implications for Polluted Environments. Front. Public Health 2016, 4, 114. [CrossRef] [PubMed]

36. Weaver, V.M.; Kim, N.-S.; Lee, B.-K.; Parsons, P.J.; Spector, J.; Fadrowski, J.; Jaar, B.G.; Steuerwald, A.J.; Todd, A.C.; Simon, D.; et al. Differences in urine cadmium associations with kidney outcomes based on serum creatinine and cystatin C. Environ. Res. 2011, 111, 1236-1242. [CrossRef] [PubMed]

37. Akerstrom, M.; Sallsten, G.; Lundh, T.; Barregard, L. Associations between Urinary Excretion of Cadmium and Proteins in a Nonsmoking Population: Renal Toxicity or Normal Physiology? Environ. Health Perspect. 2012, 121, 187-191. [CrossRef]

38. Jung, S.Y.; Kim, S.; Lee, K.; Kim, J.-Y.; Bae, W.K.; Lee, K.; Han, J.-S.; Kim, S. Association between secondhand smoke exposure and blood lead and cadmium concentration in community dwelling women: The fifth Korea National Health and Nutrition Examination Survey (2010-2012). BMJ Open 2015, 5, e008218. [CrossRef]

39. Sherlock, J.C.; Pickford, C.J.; White, G.F. Lead in alcoholic beverages. Food Addit. Contam. 1986, 3, 347-354. [CrossRef]

40. Yen, T.-H.; Lin, J.-L.; Lin-Tan, D.-T.; Hsu, C.-W.; Chen, K.-H.; Hsu, H.-H.; Pirozzi, N.; Apponi, F.; Napoletano, A.M.; Luciani, R.; et al. Blood cadmium level's association with 18-month mortality in diabetic patients with maintenance haemodialysis. Nephrol. Dial. Transpl. 2010, 26, 998-1005. [CrossRef]

(C) 2020 by the authors. Licensee MDPI, Basel, Switzerland. This article is an open access article distributed under the terms and conditions of the Creative Commons Attribution (CC BY) license (http://creativecommons.org/licenses/by/4.0/). 